\title{
Characteristics and long-term outcomes of contemporary patients with bicuspid aortic valves
}

\author{
Ahmad Masri, MD, Vidyasagar Kalahasti, MD, Saqer Alkharabsheh, MD, Lars G. Svensson, MD, PhD, \\ Joseph F. Sabik, MD, Eric E. Roselli, MD, Donald Hammer, MD, Douglas R. Johnston, MD, \\ Patrick Collier, MD, PhD, L. Leonardo Rodriguez, MD, Brian P. Griffin, MD, and Milind Y. Desai, MD
}

\begin{abstract}
Background: We sought to study the impact of surgical intervention on long-term outcomes in bicuspid aortic valve (BAV) patients who develop aortic valvular complications and/or have a concomitant aortopathy.

Methods: We studied 1890 consecutive patients with BAV (age $50 \pm 14$ years; $75 \%$ men), evaluated in the time period 2003 to 2007. Clinical and imaging data were recorded. The endpoint was a composite of death or type A aortic dissection.
\end{abstract}

Results: The mean left ventricular ejection fraction was $55 \% \pm 8 \% ; 31 \%$ had New York Heart Association class $\geq$ III aortic regurgitation, and $17 \%$ had mean aortic valve $(\mathrm{AV})$ gradient $\geq 30 \mathrm{~mm} \mathrm{Hg}$. Dilated $(\geq 4 \mathrm{~cm})$ aortic root and ascending aorta were observed in $35 \%$ and $42 \%$ of patients, respectively. At $8.1 \pm 2$ years, $918(49 \%)$ patients underwent surgery ( 883 had AV replacement and/or repair ( \pm combination procedures), 471 with ascending aortic grafting (30 had isolated aortic grafting), and 171 (9\%) events (169 deaths and 2 dissections) occurred; $0.4 \%$ was the 30 -day mortality). On multivariable Cox survival analysis, increasing age (hazard ratio [HR] 1.06, 95\% confidence interval [CI] [1.05-1.07]), increasing aortic root size (HR 1.32, 95\% CI [1.07-1.65]), decreasing LV ejection fraction (HR 1.04, 95\% CI [1.03-1.05]), and hyperlipidemia (HR 1.51, 95\% CI [1.20-1.89]) had higher associated events, and surgery related to BAV (time-dependent covariate) (HR 0.44, 95\% CI [0.31-0.70]) was associated with significantly lower events (all $P<.01$ ). Addition of surgery to $\mathrm{BAV}$ risk score (a composite of age, $\geq$ moderate-severe aortic stenosis or regurgitation) and aortic root size further improved risk stratification (the C-statistic increased from 0.65 to $0.73 ; P=.01$ ).

Conclusions: Patients with BAV have a high prevalence of AV dysfunction and concomitant aortopathy. Undergoing surgery (AV replacement and/or repair \pm AAR) was associated with a significantly lower incidence of death and/or dissection. (J Thorac Cardiovasc Surg 2016;151:1650-9)

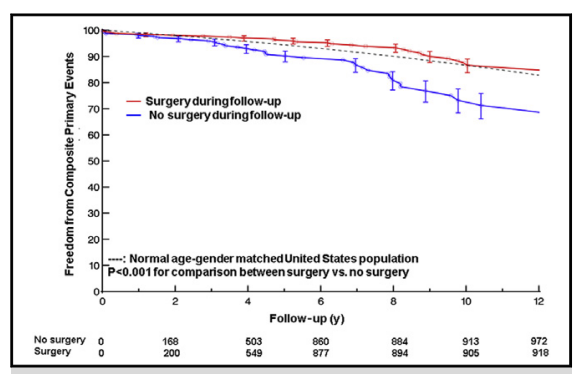

Outcomes in BAV for patients who had, versus did not have, surgery.

\section{Central Message}

In patients who had BAV, undergoing AV surgery ( \pm AAR) was associated with significantly lower death and/or dissection.

\section{Perspective}

Patients with BAV have a high prevalence of concomitant aortopathy. Undergoing surgery (AV replacement/repair \pm AAR) was associated with a significantly lower incidence of death and/or dissection in these patients.

See Editorial Commentary page 1659.
Bicuspid aortic valve (BAV) is a common congenital cardiac abnormality, affecting approximately $1 \%$ to $2 \%$ of adults. ${ }^{1}$ Prior studies suggest that, although young adults with this condition have a 20-year survival, which is comparable to that in the general population, $33 \%$ of them had

From the Valve Center, Heart and Vascular Institute, Cleveland Clinic, Cleveland, Ohio.

Received for publication Sept 15, 2015; revisions received Dec 10, 2015; accepted for publication Dec 13, 2015; available ahead of print Jan 27, 2016.

Address for reprints: Milind Y. Desai, MD, Heart and Vascular Institute, Cleveland Clinic, 9500 Euclid Ave, Desk J1-5, Cleveland, OH 44195 (E-mail: desaim2@ ccf.org).

$0022-5223 / \$ 36.00$

Copyright (c) 2016 by The American Association for Thoracic Surgery

http://dx.doi.org/10.1016/j.jtcvs.2015.12.019 cardiovascular events, and $27 \%$ needed cardiovascular surgery. ${ }^{2}$ In adult BAV patients, aortic valve (AV) dysfunction has a bimodal presentation, with significant aortic regurgitation in younger patients, and aortic stenosis in older patients. ${ }^{3-10}$

Additionally, studies have suggested a high prevalence $(20 \%-80 \%)$ of concomitant aortopathy. ${ }^{3-10}$ However,

Scanning this QR code will take you to supplemental tables for this article. 


\author{
Abbreviations and Acronyms \\ AAR = ascending aortic replacement \\ $\mathrm{AV}=$ aortic valve \\ $\mathrm{BAV}=$ bicuspid aortic valve \\ $\mathrm{CABG}=$ coronary artery bypass grafting \\ $\mathrm{CI}=$ confidence interval \\ $\mathrm{HR}=$ hazard ratio \\ $\mathrm{LV}=$ left ventricular \\ MDCT $=$ multidetector computed tomography \\ MRA = magnetic resonance angiography \\ NYHA $=$ New York Heart Association
}

these studies were relatively small and used predominantly echocardiography for characterizing aortopathy. Largescale data are lacking on long-term outcomes of BAV patients across a wider spectrum of age, especially regarding those who develop valvular complications and/or have concomitant aortopathy. Specifically, controversy remains as to the most appropriate threshold of aortic measurement at which preventive surgical intervention is indicated. ${ }^{11-13}$ We sought to study the impact of surgical intervention on long-term outcomes in contemporary BAV patients who either develop aortic valvular complications and/or have concomitant aortopathy. These were patients evaluated at our tertiary care referral center, using multimodal imaging.

\section{METHODS}

This observational cohort study involved 1890 consecutive patients who had BAV and underwent an initial transthoracic echocardiogram at our tertiary referral center between January 2003 and December 2007. We did not include patients who had undergone AV replacement (AVR) or those who had other $\geq$ moderate valvular disease. In addition, we excluded 6 patients who initially came to our institution with type A dissection (Table E1).

Appropriate approval was obtained from the institutional review board, with a waiver of individual informed consent. Clinical data were obtained through review of electronic medical records, in which data were entered prospectively at the initial encounter. Based on the available preoperative data, a Society of Thoracic Surgeons score was calculated.

\section{Echocardiography}

All patients underwent a comprehensive echocardiogram, using commercially available instruments as part of standard clinical diagnostic evaluation. Cardiac measurements were obtained according to recommendations, ${ }^{14,15}$ and left ventricular (LV) ejection fraction was calculated using Simpson's biplane method. Diastolic function was graded using recommendations. ${ }^{16}$ A semiquantitative 5-point scale was used to stratify valvular regurgitation.

Diagnosis of BAV was based on multiple views made during systole, demonstrating $2 \mathrm{AV}$ cusps; a raphe was noted when present. ${ }^{15}$ For quantification of aortic stenosis, the LV outflow tract diameter was measured on parasternal long-axis views. ${ }^{15}$ Pulsed-wave and continuous-wave Doppler were used to record velocities across the LV outflow tract and $\mathrm{AV}$, respectively, from multiple windows. The AV area was calculated using the continuity equation. Based on these calculations, severe aortic stenosis was defined as $\mathrm{AV} \leq 1 \mathrm{~cm}^{2}$, and/or mean $\mathrm{AV}$ gradient $\geq 40 \mathrm{~mm} \mathrm{Hg}$. Aortic root (at the sinuses of Valsalva) and ascending aortic diameters were recorded in the parasternal long-axis view, using a leading-edge-toleading-edge technique, at end diastole. ${ }^{14}$ Using previously described criteria, a BAV risk score (0 to 3 ) was calculated as follows: age $>30$ years, New York Heart Association (NYHA) class $\geq$ III aortic regurgitation or more than moderate aortic stenosis. ${ }^{10}$

\section{Tomographic Imaging}

Patients who had aortic root/ascending aortic dimensions $\geq 4 \mathrm{~cm}$ underwent either chest multidetector computed tomography (MDCT) or aortic magnetic resonance angiography (MRA), at the discretion of the treating physician. For MDCT, patients were scanned using standard available scanners after administration of 80 to $100 \mathrm{cc}$ of low osmolar iodinated contrast at 4 to $5 \mathrm{ml}$ per second, followed by 30 to $50 \mathrm{ml}$ of normal saline. Prospectively triggered axial or retrospectively gated spiral data were acquired. Tube voltage ranged from 100 to $120 \mathrm{kVp}$; tube current was adjusted per patient weight; and a beam pitch of 0.2 to 0.5 was utilized.

In retrospective scans, electrocardiogram-based tube current modulation was used. Aortic MRA was performed on a commercially available scanner. After initial scout images, administration of 30 to $40 \mathrm{cc}$ of gadolinium chelate, 3-dimensional thoracic aortic MRA was performed in a sagittal double oblique plane using a breath-hold (representative parameters included: field of view at $360 \times 320 \mathrm{~mm}$; a repetition time of $5.2 \mathrm{~ms}$; echo time of $1.6 \mathrm{~ms}$; and a $360 \times 260 \mathrm{~mm}$ matrix).

Subsequently, using standard software (Terra Recon, Foster City, Calif), offline 3-dimensional postprocessing of MDCT and aortic MRA images was performed using multiplanar and maximum-intensity projections. $\mathrm{Di}-$ ameters of the aortic root (midpoint of the sinus of Valsalva) and the midportion of the ascending aorta (at pulmonary artery bifurcation) were recorded. The measurements were made perpendicular to the axis of blood flow. Additionally, we indexed aortic root area (and midascending aortic area) to the patient's height. ${ }^{17}$

\section{Classification of Aortopathy}

Aortic root and ascending aortic diameters were classified as follows: normal $(<4 \mathrm{~cm})$; mild dilation $(4-4.5 \mathrm{~cm})$; moderate dilation (4.6$4.9 \mathrm{~cm})$; mildly aneurysmal $(5-5.4 \mathrm{~cm})$; and severely aneurysmal $(\geq 5.5 \mathrm{~cm})$. Additionally, a ratio of aortic root and ascending aortic area to height $\geq 10 \mathrm{~cm}^{2} / \mathrm{m}$ was considered abnormal. ${ }^{17}$ For the purpose of analysis, normal aortic dimensions $(<4 \mathrm{~cm})$ were taken from transthoracic echocardiogram; aortic dimensions $\geq 4 \mathrm{~cm}$ were taken from MDCT and/ or MRA.

\section{Surgery During Follow-up}

Surgical procedures were recorded as follows: (1) isolated AV repair/ replacement; (2) isolated ascending aortic grafting; (3) AV repair/ replacement + ascending aortic grafting; (4) AV repair/replacement + coronary artery bypass grafting (CABG); (5) ascending aortic grafting $+\mathrm{CABG}$; and (6) AV repair/replacement + ascending aortic grafting + CABG. Time to surgery was recorded. All patients underwent a comprehensive evaluation, and the decision regarding AV repair or replacement was based on existing valvular guidelines (ie, severe symptomatic aortic stenosis, severe symptomatic aortic regurgitation, or severe asymptomatic aortic regurgitation with severely enlarged left ventricle). ${ }^{11}$ For AAR, the decision was made based on the following criteria: ascending aortic dimension $>5 \mathrm{~cm}$, ascending aortic dimension $>4.5 \mathrm{~cm}$ with concomitant severe AV disease requiring surgery or ascending aortic cross-sectional area/height ratio $\geq 10 \mathrm{~cm}^{2}$ per meter. ${ }^{12,13}$ The final operative technique was decided by the cardiothoracic surgeon. 


\section{Outcomes}

A composite primary outcome of death or type A dissection was recorded. Mortality was confirmed via a query of national databases, death certificate, or verification with family members. In addition, the date of aortic dissection/rupture/intramural hematoma, occurring after the initial evaluation, was recorded. Follow-up was defined as the time from the initial echocardiogram to the composite outcome or last follow-up at our institution (including phone follow-up). We further categorized death as cardiac, noncardiac (eg, malignancy, cirrhosis of the liver, primary pulmonary/neurologic etiology), or unknown. A secondary outcome of death (categorized as cardiac or unknown, but excluding noncardiac deaths) plus type A dissection was recorded.

\section{Statistical Analysis}

Continuous variables are expressed as mean \pm standard deviation, and/ or median with interquartile range, and compared using the Student $t$-test (for parametric variables) and the Mann-Whitney $U$ test (for nonparametric variables). Categoric data are expressed as percentage and compared using $\chi^{2}$ analysis. For outcomes, Cox proportional hazards analysis was utilized. We created a parsimonious multivariable model incorporating various relevant variables associated with outcomes. For the secondary outcomes, patients that had a documented noncardiac death were censored at the time of event and not included in analysis.

Surgery was included as a time-dependent covariate in Cox survival analysis. For each patient undergoing surgery, we modified the analysis to include only person-time after surgery. Hazard ratios (HRs) with $95 \%$ confidence intervals (CIs) were calculated. Additionally, Kaplan-Meier survival curves were generated to determine the cumulative proportion of events over time, and comparison was made using the log-rank statistic. For surgical patients, date of surgery was considered to be "time zero" in survival-curve analysis. The survival of the 2 groups was compared to the survival of an age- and gender-matched US population (www.cdc. gov/nchs/products/life_tables).

The proportional hazards assumption was examined via inspection of Schoenfield residuals plotted against time. To establish a threshold of ascending aortic size (root or proximal ascending aorta), above which not performing ascending aortic surgery was associated with a significant increase in events, we divided the aortic sizes into ranges, with cutoffs of $\geq 4, \geq 4.5$, and $\geq 5 \mathrm{~cm}$. We subsequently conducted Cox survival analysis incorporating ascending aortic size as an independent covariate (and aortic size $<4 \mathrm{~cm}$ as a reference). In addition, the discriminative ability of various survival models was compared using the $C$ statistic. $^{18}$

Even though the Society of Thoracic Surgeons score has been validated to predict only 30-day postoperative mortality (and has not been validated for aortic surgery), we utilized it in the longer-term survival analysis, because it is a composite of many factors that are known to be associated with adverse longer-term survival in such patients. Statistical analysis was performed using SPSS version 11.5 (SPSS Inc, Chicago, Ill), Stata version 10.0 (Stata Corporation, College Station, Tex), and R 3.0.3 (R Foundation for Statistical Computing, Vienna, Austria).

\section{RESULTS}

Baseline characteristics show that a higher proportion of patients (568 [30\%]) had NYHA class $\geq$ III aortic regurgitation at initial presentation, compared with $\geq$ moderate-severe aortic stenosis $(316[17 \%])$. The mean age of patients with NYHA class $\geq$ III aortic regurgitation was significantly lower than that for patients with severe aortic stenosis ( $45 \pm 13$ vs $54 \pm 12$ years, respectively; $P<.001)$. A total of $503(27 \%)$ patients had NYHA class $\geq$ III aortic regurgitation; $251(13 \%)$ had $\geq$ moderate-severe aortic stenosis; and $65(3 \%)$ had mixed disease (both significant aortic stenosis and aortic regurgitation). A total of 825 $(44 \%)$ patients underwent additional tomographic imaging (630 had MDCT; 195 had aortic MRA). A total of 35\% patients had a dilated aortic root, and $42 \%$ had a dilated ascending aorta $(\geq 4 \mathrm{~cm})$ (Tables 1 and 2 ).

After initial evaluation, 918 (49\%) patients underwent cardiovascular surgery related to BAV. Within the surgical group, the median time from the initial evaluation to surgery was 30 days (interquartile range: 4-479 days), with 244 (27\%) patients undergoing surgery after $\geq 1$ year of initial evaluation. A significantly higher proportion of patients in the surgical group were in NYHA class $\geq$ II $(33 \%)$ or had other symptoms, such as angina and syncope. As expected, the proportion of patients with mean AV gradient $\geq 40 \mathrm{~mm} \mathrm{Hg}(18 \%$ vs $1 \%)$ and $\geq$ moderate-severe aortic regurgitation ( $41 \%$ vs $19 \%)$ was significantly higher in the surgical group than the nonsurgical group (both $P<.001$ ).

The distribution of various surgeries was as follows: 332 had (36\%) isolated AV surgery; $30(3 \%)$ had isolated aortic grafting; $388(42 \%)$ had $\mathrm{AV}$ surgery + ascending aortic grafting; $115(12 \%)$ had AV surgery + CABG; $5(0.5 \%)$ had ascending aortic grafting + CABG; and $48(6 \%)$ had $\mathrm{AV}$ surgery + ascending aortic grafting + CABG. Of 883 patients that had AV surgery, 694 patients had AV replacement; 189 had AV repair (80 isolated repair, 109 repair with AAR and/or CABG). Of 471 patients who had an AAR, $35(4 \%)$ had isolated AAR without AV surgery; 436 patients had AAR with AV surgery and/or CABG (89 patients had a composite valve and graft replacement; the rest had AAR with AV replacement/repair). Further, of the 471 patients with AAR, $94(20 \%)$ had a valve-sparing root + AAR. At last follow-up, 13 patients $(0.6 \%)$ had endocarditis, and 22 $(1 \%)$ required cardiac reoperation. The remainder of the patients were deemed to not be at a threshold where surgical intervention was justified based on prevalent guidelines; the decision to forgo surgery was made by agreement of the cardiologist and cardiothoracic surgeon.

\section{Outcomes Analysis}

The total follow-up time was 15,225 patient-years, with $74 \%$ patients having $\geq 7$ years of follow-up. At $8.1 \pm 2$ years of follow-up, $171(9 \%)$ primary events had occurred. The breakdown of these events was as follows: cardiovascular deaths $(n=120)$; documented noncardiac deaths (owing to cancer, neurologic, liver, or renal etiologies; $\mathrm{n}=49)$; and type A dissection $(\mathrm{n}=2)$. Time-tofirst-event was used as a cutoff for censoring. Immediate postoperative (30-day or initial hospitalization) mortality 
TABLE 1. Baseline characteristics of the study population

\begin{tabular}{|c|c|c|c|c|}
\hline Characteristics & $\begin{array}{l}\text { Total population } \\
\quad(n=1890)\end{array}$ & $\begin{array}{l}\text { No surgery during } \\
\text { follow-up }(n=972)\end{array}$ & $\begin{array}{c}\text { Surgery during } \\
\text { follow-up }(n=918)\end{array}$ & $P$ value \\
\hline Age (y) & $50 \pm 14$ & $48 \pm 15$ & $51 \pm 13$ & $<.001$ \\
\hline Male gender & $1422(75)$ & $701(72)$ & $721(79)$ & .003 \\
\hline Body surface area $\left(\mathrm{m}^{2}\right)$ & $2.0 \pm 0.3$ & $2.0 \pm 0.3$ & $2.0 \pm 0.3$ & .3 \\
\hline Angina & $116(6)$ & 0 & $116(13)$ & $<.001$ \\
\hline Syncope & $33(2)$ & $11(1)$ & $22(2)$ & .03 \\
\hline \multicolumn{5}{|l|}{ NYHA class } \\
\hline I & $1443(76)$ & $826(85)$ & $617(67)$ & $<.001$ \\
\hline II & $385(20)$ & $117(12)$ & $268(29)$ & \\
\hline III & $55(3)$ & $20(2)$ & $35(4)$ & \\
\hline IV & $7(0.5)$ & $3(0.3)$ & $4(0.4)$ & \\
\hline Hypertension & $1366(72)$ & $693(71)$ & $673(73)$ & .2 \\
\hline Hyperlipidemia & $820(43)$ & $407(58)$ & $413(42)$ & $<.001$ \\
\hline Diabetes mellitus & $183(10)$ & $97(10)$ & $86(9)$ & .3 \\
\hline Prior stroke & $58(3)$ & $30(3)$ & $28(3)$ & .4 \\
\hline COPD & $122(6)$ & $70(7)$ & $52(5)$ & .1 \\
\hline Obstructive CAD & $229(12)$ & $92(10)$ & $137(15)$ & $<.001$ \\
\hline Atrial fibrillation & $334(18)$ & $136(14)$ & $198(22)$ & $<.001$ \\
\hline Peripheral arterial disease & $48(3)$ & $29(3)$ & $19(3)$ & .3 \\
\hline Prior cardiac OS & $169(9)$ & $87(9)$ & $82(9)$ & .5 \\
\hline ICD & $27(1.4)$ & $15(1.5)$ & $12(1.3)$ & .4 \\
\hline Pacemaker & $57(3)$ & $20(2)$ & $37(4)$ & .01 \\
\hline Family history of BAV or aortopathy & $136(6)$ & $71(6)$ & $65(6)$ & .3 \\
\hline History of endocarditis & $48(2.5)$ & $13(1.3)$ & $35(3.8)$ & $<.001$ \\
\hline History of coarctation & $57(3)$ & $38(4)$ & $19(2)$ & .01 \\
\hline Society of Thoracic Surgeons score & $2.2 \pm 3$ & $2.2 \pm 4$ & $2.2 \pm 3$ & .4 \\
\hline Beta-blockers & $1285(68)$ & $511(53)$ & $774(84)$ & $<.001$ \\
\hline Calcium-channel blockers & $479(26)$ & $230(24)$ & $249(27)$ & .03 \\
\hline Angiotensin-converting enzyme inhibitors & $773(41)$ & $353(36)$ & $420(46)$ & $<.001$ \\
\hline Aspirin & $1255(66)$ & $490(50)$ & $765(83)$ & $<.001$ \\
\hline Statins & $893(47)$ & $404(42)$ & $489(53)$ & $<.001$ \\
\hline Aldosterone receptor blocker & $323(17)$ & $153(16)$ & $170(19)$ & .06 \\
\hline Hemoglobin (mg/dL) & $14 \pm 2$ & $14 \pm 2$ & $14 \pm 3$ & .4 \\
\hline Glomerular filtration rate $\left(\mathrm{mL} / \mathrm{min} / 1.73 \mathrm{~m}^{2}\right)$ & $85 \pm 24$ & $85 \pm 24$ & $85 \pm 20$ & .4 \\
\hline Low-density lipoprotein (mg/dL) & $106 \pm 35$ & $106 \pm 32$ & $106 \pm 33$ & .5 \\
\hline High-density lipoprotein $(\mathrm{mg} / \mathrm{dL})$ & $53 \pm 13$ & $53 \pm 13$ & $54 \pm 17$ & .2 \\
\hline
\end{tabular}

Values are $\mathrm{n}(\%)$, or mean \pm standard deviation, unless otherwise indicated. $N Y H A$, New York Heart Association; COPD, chronic obstructive pulmonary disease; CAD, coronary artery disease; $O S$, open (cardiac) surgery; $I C D$, internal cardioverter defibrillator; $B A V$, bicuspid aortic valve.

occurred in $4(0.4 \%)$ patients, whereas $10(0.5 \%)$ had a stroke, all in the surgical group ( 9 of these occurred within 30 days postoperatively).

For long-term primary outcomes, multivariable Cox proportional hazards survival analysis was used. Increasing age (HR 1.06), increasing aortic root size (HR 1.32), decreasing LV ejection fraction (HR 1.04); and hyperlipidemia (HR 1.51 ) were associated with a higher primary event rate; cardiovascular surgery related to BAV (HR 0.44) was associated with a significantly lower event rate (all $P<.01$ ) (Table 3, Model A). When respective individual predictors were substituted with BAV risk score and Society for Thoracic Surgeons score, results were similar (Table 3, Models B and C).
Survival curves demonstrated that long-term outcomes of BAV patients who underwent cardiovascular surgery during follow-up were significantly better, compared with those of patients who did not have surgery, and were similar to an age- and gender-matched US population (Figure 1). The respective 1-, 3-, 5-, and 7-year survival of the 3 groups was as follows: normal age- and gender-matched US population $(99 \%, 97 \%, 95 \%$, and $93 \%)$; surgery $(99 \%, 98 \%$, $96 \%$, and $95 \%$ ); and no surgery $(96 \%, 93 \%, 89 \%$, and $88 \%$ ). The relevant characteristics, separated on the basis of primary events, are shown in Table E2. The baseline risk factors of the 2 groups were similar. However, a significantly higher proportion of patients without events were in NYHA class $\geq$ II, had moderately or more severe aortic 
TABLE 2. Baseline imaging characteristics of the study population

\begin{tabular}{|c|c|c|c|c|}
\hline Characteristic & $\begin{array}{l}\text { Total population } \\
\quad(\mathbf{n}=\mathbf{1 8 9 0})\end{array}$ & $\begin{array}{l}\text { No surgery during } \\
\text { follow-up }(\mathrm{n}=\mathbf{9 7 2})\end{array}$ & $\begin{array}{c}\text { Surgery during } \\
\text { follow-up }(n=918)\end{array}$ & $P$ value \\
\hline LV ejection fraction (\%) & $55 \pm 8$ & $55 \pm 6$ & $55 \pm 8$ & .3 \\
\hline Indexed LV end-diastolic dimension $\left(\mathrm{cm} / \mathrm{m}^{2}\right)$ & $2.5 \pm 0.4$ & $2.5 \pm 0.5$ & $2.5 \pm 0.4$ & .5 \\
\hline Indexed LV end-systolic dimension $\left(\mathrm{cm} / \mathrm{m}^{2}\right)$ & $1.6 \pm 0.5$ & $1.6 \pm 0.5$ & $1.6 \pm 0.5$ & .5 \\
\hline Indexed left atrial dimension $\left(\mathrm{cm} / \mathrm{m}^{2}\right)$ & $1.9 \pm 0.4$ & $1.8 \pm 0.4$ & $1.9 \pm 0.4$ & .2 \\
\hline Indexed LV mass $\left(\mathrm{g} / \mathrm{m}^{2}\right)$ & $119 \pm 42$ & $108 \pm 34$ & $131 \pm 47$ & $<.001$ \\
\hline \multicolumn{5}{|l|}{ Diastolic function } \\
\hline Normal & $1207(64)$ & $661(68)$ & $546(59)$ & \multirow[t]{4}{*}{$<.001$} \\
\hline Abnormal relaxation & $569(30)$ & $292(30)$ & $277(30)$ & \\
\hline Pseudonormal & $95(5)$ & $19(2)$ & $76(9)$ & \\
\hline Restrictive filling & $19(1)$ & $3(0.3)$ & $16(1)$ & \\
\hline LV outflow tract diameter $(\mathrm{cm})$ & $2.0 \pm 0.2$ & $2.0 \pm 0.2$ & $2.0 \pm 0.2$ & 6 \\
\hline \multicolumn{5}{|l|}{ Aortic valve gradient $(\mathrm{mm} \mathrm{Hg})$} \\
\hline Peak & $25 \pm 29$ & $13 \pm 17$ & $37 \pm 33$ & $<.001$ \\
\hline Mean & $13 \pm 17$ & $7 \pm 9$ & $20 \pm 19$ & $<.001$ \\
\hline \multicolumn{5}{|l|}{ Mean aortic valve gradient $(\mathrm{mm} \mathrm{Hg})$} \\
\hline $30-40$ & $141(8)$ & $21(2)$ & $121(13)$ & $<.001$ \\
\hline$\geq 40$ & $175(9)$ & $11(1)$ & $164(18)$ & $<.001$ \\
\hline Calculated aortic valve area & $1.3 \pm 0.5$ & $1.5 \pm 0.5$ & $1.2 \pm 0.4$ & $<.001$ \\
\hline \multicolumn{5}{|l|}{ Aortic valve cusp orientation } \\
\hline Right-left fusion & $1620(86)$ & $833(86)$ & $787(86)$ & \multirow[t]{3}{*}{.9} \\
\hline Right and noncusp fusion & $219(12)$ & $114(12)$ & $105(11)$ & \\
\hline Left and noncusp fusion & $51(3)$ & $25(3)$ & $26(3)$ & \\
\hline \multicolumn{5}{|l|}{ Aortic regurgitation } \\
\hline None & $684(36)$ & $423(44)$ & $261(28)$ & \multirow[t]{5}{*}{$<.001$} \\
\hline Mild & $303(16)$ & $169(17)$ & $134(15)$ & \\
\hline Moderate & $335(18)$ & $191(20)$ & $144(16)$ & \\
\hline Moderate-severe & $330(18)$ & $146(15)$ & $184(20)$ & \\
\hline Severe & $238(13)$ & $43(4)$ & $195(21)$ & \\
\hline \multicolumn{5}{|l|}{ Bicuspid aortic valve risk score } \\
\hline 0 & $114(6)$ & $99(10)$ & $15(2)$ & \multirow[t]{4}{*}{$<.001$} \\
\hline 1 & $1030(54)$ & $695(32)$ & $335(37)$ & \\
\hline 2 & $690(37)$ & $171(18)$ & $519(57)$ & \\
\hline 3 & $56(3)$ & $7(0.7)$ & $49(5)$ & \\
\hline \multicolumn{5}{|l|}{ Mitral regurgitation } \\
\hline None & $1459(77)$ & $778(80)$ & $681(75)$ & \multirow[t]{3}{*}{.02} \\
\hline Mild & $284(15)$ & $136(14)$ & $148(15)$ & \\
\hline Moderate & $147(8)$ & $58(6)$ & $89(10)$ & \\
\hline \multicolumn{5}{|l|}{ Tricuspid regurgitation } \\
\hline None & $1479(78)$ & $762(78)$ & $717(78)$ & \multirow[t]{3}{*}{.8} \\
\hline Mild & $312(17)$ & $155(18)$ & $157(17)$ & \\
\hline Moderate & $99(5)$ & $55(4)$ & $44(5)$ & \\
\hline Right ventricular systolic pressure $(\mathrm{mm} \mathrm{Hg})$ & $16 \pm 17$ & $16 \pm 16$ & $16 \pm 14$ & 6 \\
\hline Aortic root $(\mathrm{cm})$ & $3.6 \pm 0.8$ & $3.4 \pm 0.7$ & $3.9 \pm 0.8$ & $<.001$ \\
\hline Aortic root cross-sectional area/height ratio $\geq 10 \mathrm{~cm}^{2} / \mathrm{m}$ & $126(7)$ & $23(2)$ & $103(11)$ & $<.001$ \\
\hline \multicolumn{5}{|l|}{ Aortic root $(\mathrm{cm})$} \\
\hline$<4$ & $1223(65)$ & $740(76)$ & $483(53)$ & \multirow[t]{5}{*}{$<.001$} \\
\hline $4-4.5$ & $468(25)$ & $189(19)$ & $279(30)$ & \\
\hline 4.6-4.9 & $117(6)$ & $31(3)$ & $86(9)$ & \\
\hline $5-5.4$ & $66(3)$ & $10(1)$ & $56(6)$ & \\
\hline$>5.4$ & $16(1)$ & $2(0.2)$ & $14(2)$ & \\
\hline Ascending aortic dimension $(\mathrm{cm})$ & $3.9 \pm 0.8$ & $3.6 \pm 0.7$ & $4.2 \pm 0.9$ & $<.001$ \\
\hline Ascending aortic cross-sectional area/height ratio $\geq 10 \mathrm{~cm}^{2} / \mathrm{m}$ & $321(17)$ & $55(6)$ & $266(29)$ & $<.001$ \\
\hline
\end{tabular}


TABLE 2. Continued

\begin{tabular}{|c|c|c|c|c|c|}
\hline & Characteristic & $\begin{array}{l}\text { Total population } \\
\quad(n=1890)\end{array}$ & $\begin{array}{l}\text { No surgery during } \\
\text { follow-up }(\mathrm{n}=972)\end{array}$ & $\begin{array}{c}\text { Surgery during } \\
\text { follow-up }(n=918)\end{array}$ & $P$ value \\
\hline \multicolumn{6}{|c|}{ Ascending aorta $(\mathrm{cm})$} \\
\hline$<4$ & & $1102(58)$ & $714(74)$ & $388(42)$ & $<.001$ \\
\hline $4-4.5$ & & $390(21)$ & $174(18)$ & $216(23)$ & \\
\hline $4.6-4.9$ & & $178(9)$ & $52(5)$ & $126(14)$ & \\
\hline $5-5.4$ & & $160(9)$ & $26(3)$ & $134(15)$ & \\
\hline$>5.4$ & & $60(3)$ & $6(0.3)$ & $54(6)$ & \\
\hline
\end{tabular}

Values are $\mathrm{n}(\%)$ or mean \pm standard deviation, unless otherwise indicated. $L V$, Left ventricular.

regurgitation, and an aortopathy, which resulted in a higher proportion of patients undergoing surgery for BAV during follow-up $(51 \%$ in the no-event group vs $27 \%$ in the event group; $P<.001)$.

An incremental association was found of BAV risk score, aortic root dimensions, and surgery with the primary

TABLE 3. Multivariable Cox proportional hazards analysis for the primary endpoint of long-term death and type A aortic dissection

\begin{tabular}{lcc}
\hline \multicolumn{1}{c}{ Variable } & $\begin{array}{c}\text { Hazard ratio } \\
(\mathbf{9 5} \% \mathbf{C I})\end{array}$ & $\boldsymbol{P}$ value \\
\hline Model A & $1.06(1.05-1.07)$ & $<.001$ \\
Age & $1.32(1.07-1.65)$ & $<.001$ \\
Increasing aortic root size & $1.04(1.03-1.05)$ & $<.001$ \\
Decreasing left ventricular ejection & & \\
$\quad$ fraction & $1.51(1.20-1.89)$ & $<.001$ \\
$\quad$ Hyperlipidemia & $0.44(0.31-0.70)$ & $<.001$ \\
$\quad$ Surgery related to bicuspid aortic valve & & \\
$\quad$ (time-dependent covariate) & & \\
Model B & $1.41(1.10-1.94)$ & .02 \\
$\quad$ Bicuspid aortic valve risk score & $1.43(1.12-1.76)$ & .002 \\
$\quad$ Increasing aortic root size & $1.04(1.02-1.05)$ & $<.001$ \\
$\quad$ Decreasing left ventricular ejection & & \\
$\quad$ fraction & $1.47(1.17-1.81)$ & $<.001$ \\
$\quad$ Hyperlipidemia & $0.45(0.31-0.66)$ & $<.001$ \\
$\quad$ Surgery related to bicuspid aortic valve & & \\
$\quad$ (time-dependent covariate) & & \\
Model C & & \\
$\quad$ Society of Thoracic Surgeons score & $1.31(1.25-1.35)$ & $<.001$ \\
Increasing aortic root size & $1.22(1.08-1.38)$ & .01 \\
$\quad$ Surgery related to bicuspid aortic valve & $0.31(0.22-0.44)$ & $<.001$ \\
$\quad$ (time-dependent covariate) & & \\
\hline
\end{tabular}

The following predictors were considered for multivariable analysis: age, gender, symptoms, coronary artery disease, hypertension, hyperlipidemia, atrial fibrillation, prior cardiac surgery, glomerular filtration rate, left ventricular ejection fracrion, medications, mean aortic valve gradient, aortic regurgitation, right ventricular systolic pressure, surgery related to BAV, type of cardiac surgery performed, time to cardiac surgery, and aortic root size. Because of collinearity between ascending aortic and aortic root dimensions, ascending aortic dimensions were not entered in the model. However, when ascending aortic dimensions were substituted for aortic root size, the results were similar. When the largest diameters between aortic roots or ascending aortas were utilized, results were similar. In model B, the predictors that constituted the BAV risk score were not considered for analysis. Similarly, in Model C, the predictors that constitute the Society of Thoracic Surgeons score were not considered for analysis. $C I$, Confidence interval. outcome (Figure 2). The $\chi^{2}$ for the model that added aortic root dimensions to BAV risk score was significantly higher than that for BAV risk score $(29$ vs $15, P<.001)$. Further addition of surgery to the model significantly increased the chi-square value ( 49 vs $29, P<.001$ ). Similarly, addition of aortic root size to the BAV risk score improved risk stratification for primary outcomes (the $C$-statistic increased from 0.59 [0.55-0.65] to 0.65 [0.61-0.69], $P=.02$ ). The addition of surgery to the BAV risk score and aortic root size further improved risk stratification (the $C$-statistic increased to 0.73 [0.69-0.77]; $P=.01$ ). The results were similar if ascending aortic dimensions were substituted for aortic root dimensions.

To assess the risk of a primary adverse event with increasing aortic dimensions in patients who had AARs $(\mathrm{n}=471)$, we performed Cox survival analysis incorporating aortic size as an independent covariate at various size cutoffs $(\geq 4, \geq 4.5$, and $\geq 5 \mathrm{~cm})$. Ascending aortic size $<4 \mathrm{~cm}$ was used as a reference. Figure 3 demonstrates the HRs for primary events plotted against aortic size cutoffs. The hazard of primary events was significantly higher at a threshold of $\geq 4.5 \mathrm{~cm}$ if patients had not had concomitant AAR, compared with those who had (4\% vs $8 \%$; Cox survival $P=.02$ ). At an aortic size cutoff of $\geq 4 \mathrm{~cm}$, no significant increase was found in primary events in those who did versus did not have AAR $(5 \%$ vs 7\%; Cox survival $P=.1$ ).

The data on multivariable Cox proportional survival analysis for the secondary outcome (number of events $=122$ ) were similar, as follows: increasing age (HR 1.05, 95\% CI [1.04-1.06]); increasing aortic root size (HR 1.27, 95\% CI [1.05-1.56]); decreasing LV ejection fraction (HR $1.05,95 \%$ CI [1.03-1.07]); and hyperlipidemia (HR 1.44, $95 \% \mathrm{CI}[1.17-1.88])$ were associated with higher secondary events, whereas cardiovascular surgery related to BAV (HR $0.50,95 \%$ CI [0.35-0.76]) was associated with significantly lower secondary events (all $P<.01$ ).

Two patients (both women, ages 35 and 49 years) presented at 253 and 1218 days, respectively, after their initial clinical evaluation with type A dissection. At the time of presentation with dissection, the aortic root dimensions 


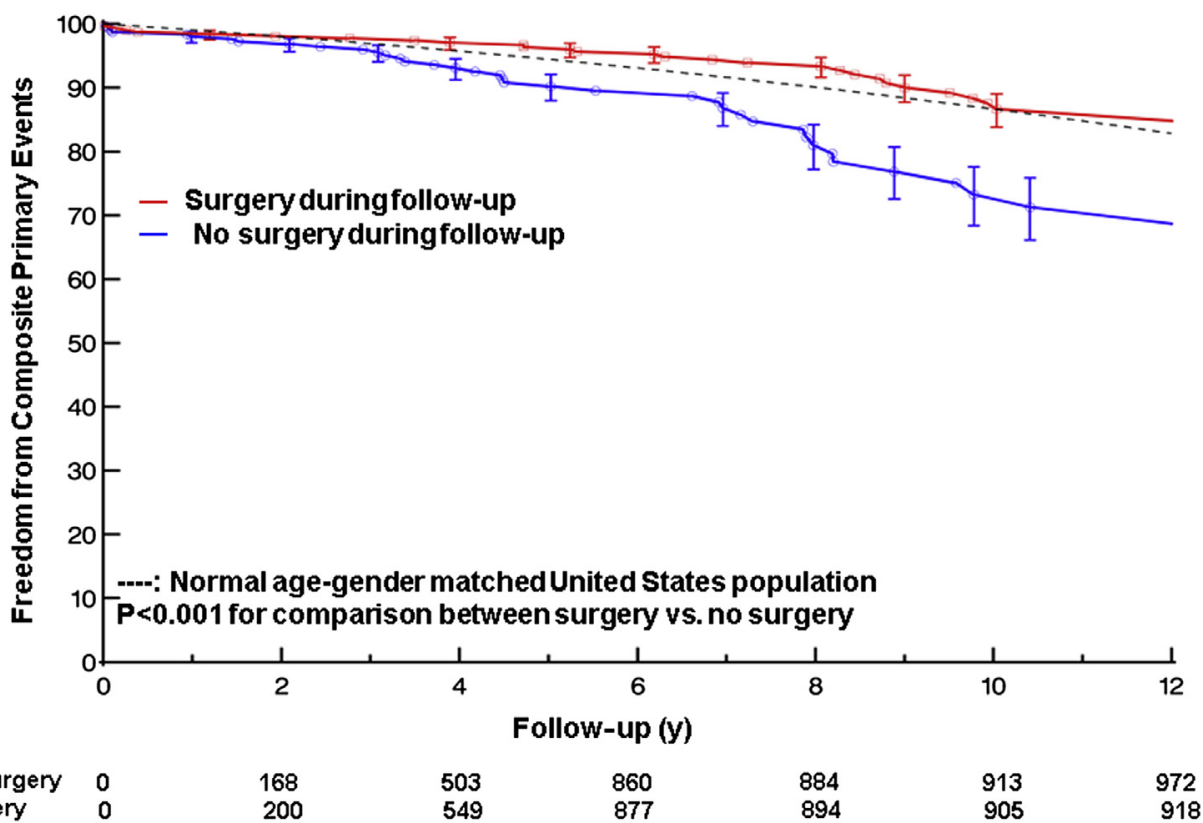

FIGURE 1. Kaplan-Meier survival curves of the study population, separated based on whether patients had surgery related to bicuspid aortic valve (BAV) or not compared with age- and gender-matched US population.

were 3.7 and $4.5 \mathrm{~cm}$, and the ascending aortic dimensions were 4.5 and $5.5 \mathrm{~cm}$, respectively. Both patients underwent emergent AVR + AAR and were alive at the time of writing.

\section{DISCUSSION}

In this large, observational, cohort study of BAV patients undergoing multimodal imaging evaluation, a low rate of composite events occurred $(9 \%)$, with only 2 patients $(0.1 \%)$ presenting with type $\mathrm{A}$ dissection. The very low rate of dissections likely reflects the higher use of prophylactic concomitant AAR at the time of AV surgery. During follow-up, $49 \%$ of patients underwent surgery related to BAV, with approximately $36 \%$ of those undergoing isolated $\mathrm{AV}$ repair or replacement, 3\% isolated AAR, and the remainder a combination procedure. Although the median time to surgery was 30 days, $27 \%$

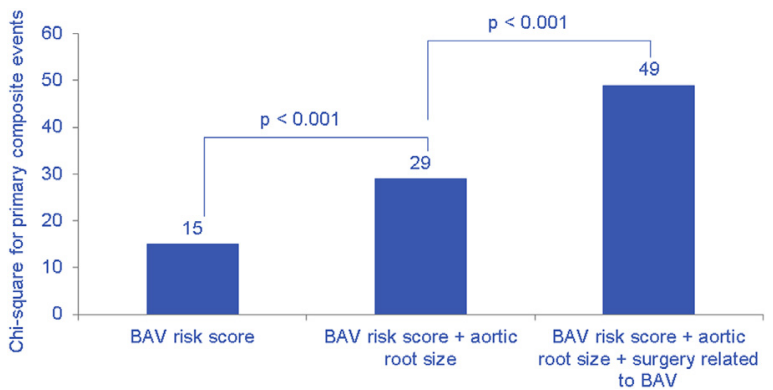

FIGURE 2. Incremental utility of BAV risk score, aortic root size, and BAV surgery. Results were similar if ascending aortic dimensions were entered into the model instead of aortic root dimensions. BAV, Bicuspid aortic valve. of patients had surgery initially deferred for $\geq 1$ year before they were crossed over to the surgical group. This finding confirms prior reports that showed a high rate of surgical intervention in BAV patients over their lifetime, secondary to either valvular dysfunction or associated aortopathies. ${ }^{2,10,19}$

Increasing ascending aortic size (root or proximal aorta) was associated with a higher proportion of events, whereas surgery related to BAV was associated with improved freedom from composite events. In fact, long-term outcomes of BAV patients who underwent surgery during follow-up were significantly better than those for patients who did not, and were similar to those for a normal, ageand gender-matched US population. We demonstrate that the addition of aortic dimensions and subsequent cardiovascular surgery to the BAV risk score provided incremental prognostic utility. Additionally, in patients with a concomitant aortopathy (ascending aortic dimensions $\geq 4.5 \mathrm{~cm}$ ), performing AAR was associated with freedom from primary events (Table E2).

Multiple previous reports have described long-term outcomes in BAV patients. ${ }^{2,10,19}$ In the study by Michelena and colleagues, ${ }^{2}$ the natural history of 212 normally functioning or minimally dysfunctional BAV patients (mean age: 32 years) was studied. The authors demonstrate a $90 \%$ survival at 20 years, but a $33 \%$ rate of composite cardiovascular events, and a $27 \%$ need for cardiovascular surgery in that timeframe. Another study by Tzemos and colleagues ${ }^{10}$ studied 642 consecutive patients with BAV (mean age: 35 years), demonstrating a low mortality $(4 \%)$ and dissection rate $(2 \%)$ during almost 9 years of 


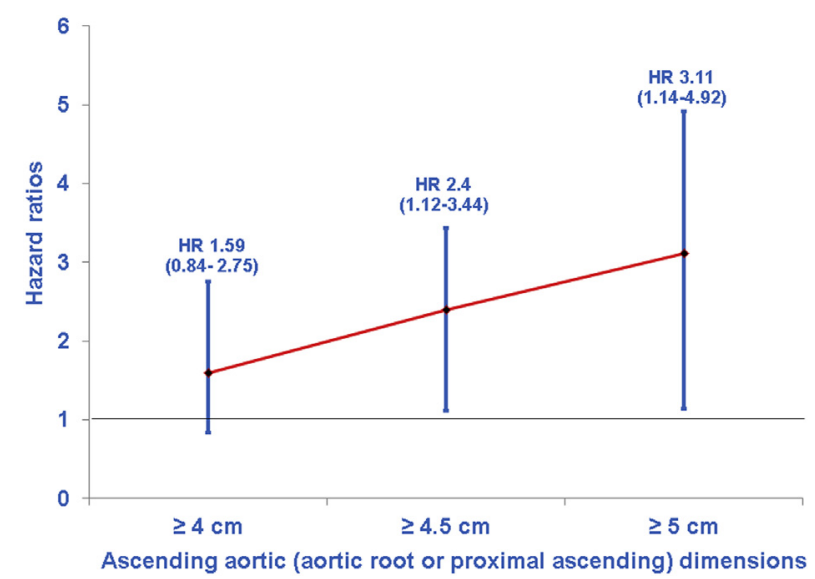

FIGURE 3. Hazard ratios (with $95 \%$ confidence intervals) for primary events, plotted against various ascending aortic (root or proximal ascending) cutoffs for undergoing concomitant AAR. The figure demonstrates that an aortic size $\geq 4.5 \mathrm{~cm}$ with no concomitant AAR was associated with a higher hazard for primary events. However, if a cutoff of $\geq 4 \mathrm{~cm}$ was used for ascending aortic surgery, the association with primary events was not significant. The reference group was made up of those with aortic dimensions $\leq 4 \mathrm{~cm}$. $H R$, Hazard ratio.

follow-up. However, $22 \%$ of patients needed cardiovascular surgery during that timeframe. ${ }^{1}$ In a follow-up study by Michelena and colleagues, ${ }^{19}$ the rate of aortic dissection at 16 years of follow-up was low, but significantly higher than that in the general population. However, only $9 \%$ of patients had a concomitant aortopathy. ${ }^{19}$

Our institution has recently reported results of surgery related to BAV. In one study of 728 patients who underwent $\mathrm{AV}$ repair, a 30-day mortality of $0.4 \%$ was found, with a $78 \%$ freedom from reoperation at 10 years. ${ }^{20}$ In another study of 366 patients, excellent outcomes have been reported after AV-preserving repair, compared with AV replacement. ${ }^{21}$ Prior data have demonstrated that if an ascending aortic segment $>4.5 \mathrm{~cm}$ is excised at the time of concurrent $\mathrm{AV}$ surgery, the risk of subsequent events is low. ${ }^{22}$

In the current study, we included consecutive patients with BAV from within a narrow timeframe (2003-2007), to ensure uniformity of medical therapies, surgical techniques, and adherence to similar guideline recommendations. The diagnosis of BAV was made locally or at our institution, based on clinical evaluation (including a family history, a heart murmur, and/or a workup of symptoms). The study population was significantly older (mean age: 50 years) than that in previous reports, and we specifically examined the predictive contribution of aortic size to long-term outcomes. ${ }^{2,10,19}$

In contrast to previous reports, we incorporated multimodal imaging, including 3-dimensional tomographic assessment, especially in diagnosis and management of concomitant aortopathies. Based on current guidelines, timing of AV surgery in patients with significant stenosis or regurgitation who are symptomatic or have LV dysfunction is fairly standard. ${ }^{11}$ However, significant controversy surrounds the threshold above which pre-emptive aortic replacement surgery is recommended in BAV patients. The aortic guidelines suggest that aortic surgery be performed at a threshold of $5 \mathrm{~cm}$ (or at an aortic crosssectional area-to-height ratio of $\left.\geq 10 \quad \mathrm{~cm}^{2} / \mathrm{m}\right){ }^{12,13}$ However, the recently published 2014 American Heart Association/American College of Cardiology valve guidelines ${ }^{11}$ recommend increasing the threshold for isolated replacement of the aorta to $5.5 \mathrm{~cm}$, with the justification that the rate of dissection in the previously mentioned studies was very low. ${ }^{10,11,19}$

However, in the series by Tzemos and colleagues, ${ }^{10}$ a total of 38 of 642 patients had interventions of their ascending aorta, but no data indicate the threshold at which these interventions were done, which may mask the absolute risk of complications in such patients, especially given that very few patients had an aorta that was dilated $\geq 5.5 \mathrm{~cm}$ in that series. In the study by Michelena and colleagues, ${ }^{19}$ a total of 49 of 416 patients underwent prophylactic surgery for a dilated ascending aorta, but the threshold used for surgical intervention was unclear. On the other hand, in the international registry of acute aortic dissection (in which a proportion of patients had a BAV), ${ }^{23}$ out of 591 type A dissections, $40 \%$ and $59 \%$ had aortic diameters of $<5 \mathrm{~cm}$ and $<5.5 \mathrm{~cm}$, respectively.

In addition, older data have suggested that $15 \%$ of patients presenting with acute aortic dissection had BAV. ${ }^{1}$ It is an important practice to perform at least 1 detailed assessment of the aorta in BAV patients, to ensure the absence of concomitant aortopathy, because, based on our data, the low risk of dissections may potentially reflect the protective role of prophylactic ascending aortic surgery. Indeed, in the current study, we demonstrate that patients with ascending aortic dimensions $\geq 4.5 \mathrm{~cm}$ who underwent AAR had an associated improvement in freedom from primary events. However, any justification for surgery must be supported by excellent outcomes from an experienced center for prophylactic surgery. ${ }^{22}$

In addition, these findings need to be replicated prospectively. Potential reasons for the nonsurgical group faring worse are under-recognition of symptoms in the setting of significant valve deterioration, or aortic rupture in an undocumented aortopathy setting, both of which could delay surgical referral. We have demonstrated, in other disease processes, that patients often underestimate symptoms related to valvular disease, and in many instances, stress testing may be necessary to unmask latent symptoms and guide surgical decision making. ${ }^{24-26}$

\section{Limitations}

Because this was an observational study from a single center that was retrospectively analyzed, there is potential 
for referral and selection bias. However, the data entry and surgical decision making occurred prospectively. We did not include surgery as an endpoint in survival analysis because of the relatively short time between initial evaluation and surgery. In contract to the current study, the BAV risk score was originally developed to predict primary cardiac events, including cardiac death, intervention on the AV or ascending aorta, aortic dissection or aneurysm, or congestive heart failure requiring hospital admission. This method of development likely reflects the tertiary referral nature of our practice, where a significant proportion of patients who are followed longitudinally elsewhere are sent specifically for surgical care.

Given that a substantial proportion of patients underwent surgery for concomitant aortopathy, the current study does not enable us to generate conclusions about an aortic size threshold above which the rate of dissection increases if the patient continues without surgery. To ascertain that threshold, a natural history study of BAV patients who had multimodal imaging might be needed. We report allcause mortality as the primary endpoint, as opposed to cardiac mortality. However, on secondary outcomes analysis, in which documented non-cardiac deaths were excluded, the basic results were similar. However, all-cause mortality has been demonstrated to be more objective and unbiased than cardiac mortality. ${ }^{27,28}$ Finally, one possibility is that some patients who presented with a type A dissection at a local facility were not accounted for in survival analysis.

\section{CONCLUSIONS}

In an observational study of patients who have BAV presenting with significant aortic stenosis and/or aortic regurgitation, a high proportion have a concomitant aortopathy; however, the incidence of long-term events (death and/or dissection) is low. Patients who underwent surgery (AV replacement and/or repair $+/-$ AAR) had survival similar to that of a matched general population. A combination of composite BAV risk score, aortic dimensions, and subsequent cardiovascular surgery related to BAV provides incremental prognostic utility.

\section{Conflict of Interest Statement}

Dr Johnston reports consultant fees from Edwards, KEF, St. Jude Medical, and iVHR. Dr Roselli reports consulting fees for Medtronic, Sorin, and St. Jude. Dr Sabik reports consulting fees for Medtronic and Sorin. All other authors have nothing to disclose with regard to commercial support.

\section{References}

1. Braverman AC, Guven H, Beardslee MA, Makan M, Kates AM, Moon MR. The bicuspid aortic valve. Curr Probl Cardiol. 2005;30:470-522.

2. Michelena HI, Desjardins VA, Avierinos JF, Russo A, Nkomo VT, Sundt TM, et al. Natural history of asymptomatic patients with normally functioning or minimally dysfunctional bicuspid aortic valve in the community. Circulation. 2008;117:2776-84.
3. Della Corte A, Bancone C, Quarto C, Dialetto G, Covino FE, Scardone M, et al Predictors of ascending aortic dilatation with bicuspid aortic valve: a wide spectrum of disease expression. Eur J Cardiothorac Surg. 2007;31:397-404; discussion 404-5.

4. Siu SC, Silversides CK. Bicuspid aortic valve disease. J Am Coll Cardiol. 2010; $55: 2789-800$

5. Fedak PW, Verma S, David TE, Leask RL, Weisel RD, Butany J. Clinical and pathophysiological implications of a bicuspid aortic valve. Circulation. 2002; 106:900-4.

6. Hahn RT, Roman MJ, Mogtader AH, Devereux RB. Association of aortic dilation with regurgitant, stenotic and functionally normal bicuspid aortic valves. J Am Coll Cardiol. 1992;19:283-8.

7. Tadros TM, Klein MD, Shapira OM. Ascending aortic dilatation associated with bicuspid aortic valve: pathophysiology, molecular biology, and clinical implications. Circulation. 2009;119:880-90.

8. Thanassoulis G, Yip JW, Filion K, Jamorski M, Webb G, Siu SC, et al. Retrospective study to identify predictors of the presence and rapid progression of aortic dilatation in patients with bicuspid aortic valves. Nat Clin Pract Cardiovasc Med. 2008;5:821-8.

9. Nistri S, Sorbo MD, Marin M, Palisi M, Scognamiglio R, Thiene G. Aortic root dilatation in young men with normally functioning bicuspid aortic valves. Heart. 1999;82:19-22.

10. Tzemos N, Therrien J, Yip J, Thanassoulis G, Tremblay S, Jamorski MT, et al. Outcomes in adults with bicuspid aortic valves. JAMA. 2008;300:1317-25.

11. Nishimura RA, Otto CM, Bonow RO, Carabello BA, Erwin JP III, Guyton RA, et al. 2014 AHA/ACC guideline for the management of patients with valvular heart disease: executive summary: a report of the American College of Cardiology/American Heart Association Task Force on Practice Guidelines. Circulation. 2014; 129:2440-92.

12. Hiratzka LF, Bakris GL, Beckman JA, Bersin RM, Carr VF, Casey DE Jr, et al. American Association for Thoracic Surgery, American College of Radiology, American Stroke Association, Society of Cardiovascular Anesthesiologists, Society for Cardiovascular Angiography and Interventions, Society of Interventional Radiology, Society of Thoracic Surgeons, and Society for Vascular Medicine. 2010 ACCF/AHA/AATS/ACR/ASA/SCA/ SCAI/SIR/STS/SVM guidelines for the diagnosis and management of patients with thoracic aortic disease: a report of the American College of Cardiology Foundation/American Heart Association Task Force on Practice Guidelines. Circulation. 2010;121:e266-369.

13. Svensson LG, Adams DH, Bonow RO, Kouchoukos NT, Miller DC, O'Gara PT, et al. Aortic valve and ascending aorta guidelines for management and quality measures: executive summary. Ann Thorac Surg. 2013;95: $1491-505$.

14. Lang RM, Bierig M, Devereux RB, Flachskampf FA, Foster E, Pellikka PA, et al. Recommendations for chamber quantification: a report from the American Society of Echocardiography's Guidelines and Standards Committee and the Chamber Quantification Writing Group, developed in conjunction with the European Association of Echocardiography, a branch of the European Society of Cardiology. J Am Soc Echocardiogr. 2005;18:1440-63.

15. Baumgartner H, Hung J, Bermejo J, Chambers JB, Evangelista A, Griffin BP, et al. Echocardiographic assessment of valve stenosis: EAE/ASE recommendations for clinical practice. J Am Soc Echocardiogr. 2009;22:1-23; quiz, $101-2$.

16. Nagueh SF, Appleton CP, Gillebert TC, Marino PN, Oh JK, Smiseth OA, et al. Recommendations for the evaluation of left ventricular diastolic function by echocardiography. J Am Soc Echocardiogr. 2009;22:107-33.

17. Svensson LG, Kim KH, Lytle BW, Cosgrove DM. Relationship of aortic crosssectional area to height ratio and the risk of aortic dissection in patients with bicuspid aortic valves. J Thorac Cardiovasc Surg. 2003;126:892-3.

18. Uno H, Cai T, Pencina MJ, D'Agostino RB, Wei LJ. On the C-statistics for evaluating overall adequacy of risk prediction procedures with censored survival data. Stat Med. 2011;30:1105-17.

19. Michelena HI, Khanna AD, Mahoney D, Margaryan E, Topilsky Y, Suri RM, et al. Incidence of aortic complications in patients with bicuspid aortic valves. JAMA. 2011;306:1104-12.

20. Svensson LG, Al Kindi AH, Vivacqua A, Pettersson GB, Gillinov AM, Mihaljevic T, et al. Long-term durability of bicuspid aortic valve repair. Ann Thorac Surg. 2014;97:1539-47; discussion 1548.

21. Svensson LG, Batizy LH, Blackstone EH, Gillinov AM, Moon MC, D'Agostino RS, et al. Results of matching valve and root repair to aortic valve and root pathology. J Thorac Cardiovasc Surg. 2011;142:1491-8.e7. 
22. Svensson LG, Kim KH, Blackstone EH, Rajeswaran J, Gillinov AM, Mihaljevic T, et al. Bicuspid aortic valve surgery with proactive ascending aorta repair. J Thorac Cardiovasc Surg. 2011;142:622-9. e621-3.

23. Pape LA, Tsai TT, Isselbacher EM, Oh JK, O'Gara PT, Evangelista A, et al. Aortic diameter $>$ or $=5.5 \mathrm{~cm}$ is not a good predictor of type A aortic dissection: observations from the International Registry of Acute Aortic Dissection (IRAD). Circulation. 2007;116:1120-7.

24. Desai MY, Smedira NG, Bhonsale A, Thamilarasan M, Lytle BW, Lever HM. Symptom assessment and exercise impairment in surgical decision making in hypertrophic obstructive cardiomyopathy: relationship to outcomes. J Thorac Cardiovasc Surg. 2015;150:928-35.e1.

25. Naji P, Griffin BP, Barr T, Asfahan F, Gillinov AM, Grimm RA, et al. Importance of exercise capacity in predicting outcomes and determining optimal timing of surgery in significant primary mitral regurgitation. J Am Heart Assoc. 2014;3 e001010.

26. Naji P, Griffin BP, Asfahan F, Barr T, Rodriguez LL, Grimm R, et al. Predictors of long-term outcomes in patients with significant myxomatous mitral regurgitation undergoing exercise echocardiography. Circulation. 2014;129:1310-9.

27. Lauer MS, Blackstone EH, Young JB, Topol EJ. Cause of death in clinical research: time for a reassessment? J Am Coll Cardiol. 1999;34:618-20.

28. Boyle CA, Decoufle P. National sources of vital status information: extent of coverage and possible selectivity in reporting. Am J Epidemiol. 1990;131:160-8.

Key Words: bicuspid aortic valve, aortopathy, surgery, and outcomes

\title{
EDITORIAL COMMENTARY
}

\section{Knife saves life}

\author{
Hiroo Takayama, MD, PhD
}

From the Department of Surgery, Columbia University Medical Center, New York, NY.

Disclosures: Author has nothing to disclose with regard to commercial support.

Received for publication Dec 21, 2015; accepted for publication Dec 21, 2015.

Address for reprints: Hiroo Takayama, MD, PhD, 177 Fort Washington Ave, New York, NY 10032 (E-mail:

hirofu2@hotmail.com).

J Thorac Cardiovasc Surg 2016;151:1659-60

$0022-5223 / \$ 36.00$

Copyright (C) 2016 by The American Association for Thoracic Surgery

http://dx.doi.org/10.1016/j.jtcvs.2015.12.069

Although it is the most common congenital anomaly of the heart, much remains unknown about bicuspid aortic valve (BAV), and substantial new information continues to be revealed and debated. One example is the conflict regarding the guidelines on the aortic diameter threshold for surgical intervention for BAV-associated ascending aneurysms. The 2013 Society of Thoracic Surgeons practice guidelines recommend that $5.0 \mathrm{~cm}$ be used as the threshold, whereas the 2014 American Heart Association/ American College of Cardiology guidelines suggest a threshold of $5.5 \mathrm{~cm}$ (although the 2010 guideline from these 2 institutions was much more aggressive, suggesting a cutoff of $4.5 \mathrm{~cm}){ }^{1,2}$ Development of an evidence-based consensus on this issue calls for sound additional information.

Masri and colleagues ${ }^{3}$ reported long-term follow-up outcomes on BAV patients. The included patients were carefully followed, and those who had developed the guideline-recommended indications underwent surgical interventions. Although most of their findings are confirmatory, rather than novel, this study stands out among others because of its large sample size (1890

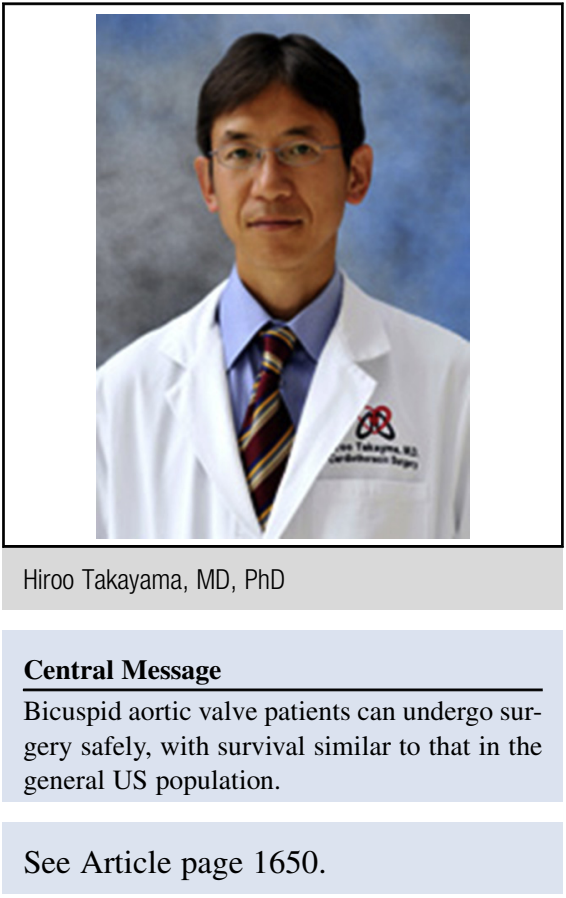

consecutive patients). During the observation period of approximately 8 years, many patients (approximately $50 \%$ ) required surgical therapy, and the associated aortic dilation was common: $35 \%$ of the root and $42 \%$ of the ascending aorta.

The authors ${ }^{3}$ added a unique perspective by addressing the effect of the surgical interventions on the long-term outcomes of their cohort. The BAV patients who underwent aortic valve surgery with or without ascending 
TABLE E1. Characteristics of 6 patients whose initial presentation was type A aortic dissection (patients excluded from the current analysis)

\begin{tabular}{lcccccc}
\hline \multicolumn{1}{c}{ Characteristics } & Patient 1 & Patient 2 & Patient 3 & Patient 4 & Patient 5 & Patient 6 \\
\hline Age $(\mathrm{y})$ & 60 & 37 & 57 & 43 & 35 & 38 \\
Gender & Male & Male & Male & Male & Male & Female \\
STS score & 1.08 & 1.52 & 0.81 & 2.04 & 0.78 & 1.15 \\
Aortic root $(\mathrm{cm})$ & 5 & 7.2 & 3.5 & 4.4 & 5.5 & 2.7 \\
Ascending aorta $(\mathrm{cm})$ & 4.2 & 3.8 & 9.9 & 4.8 & 2.6 \\
Type of surgery & AVR + AAR & AVR + AAR & AVR + AAR & AVR + AAR & Valve-sparing aortic root + AAR & AVR + AAR \\
Death during follow-up & No & Yes & No & No & No & Yes \\
\hline
\end{tabular}

$S T S$, Society of Thoracic Surgeons; $A V R$, aortic valve replacement; $A A R$, ascending aortic replacement.

TABLE E2. Relevant baseline characteristics of the study population, separated on the basis of events during follow-up

\begin{tabular}{|c|c|c|c|}
\hline Characteristics & $\begin{array}{l}\text { No events } \\
(\mathrm{n}=1719)\end{array}$ & $\begin{array}{l}\text { Composite events } \\
(\mathrm{n}=171)\end{array}$ & $P$ value \\
\hline Age $(y)$ & $50 \pm 14$ & $51 \pm 13$ & .2 \\
\hline Male gender & 75 & 78 & .7 \\
\hline NYHA class $\geq$ II & 24 & 42 & $<.001$ \\
\hline Hypertension & 73 & 69 & .2 \\
\hline Obstructive coronary artery disease & 12 & 13 & .1 \\
\hline Society of Thoracic Surgeons score & $2.2 \pm 4$ & $2.4 \pm 3$ & .1 \\
\hline Beta-blockers & 68 & 64 & .12 \\
\hline Angiotensin-converting enzyme inhibitors & 41 & 41 & .5 \\
\hline Angiotensin receptor blockers & 17 & 18 & .4 \\
\hline Glomerular filtration rate $\left(\mathrm{mL} / \mathrm{min} / 1.73 \mathrm{~m}^{2}\right)$ & $85 \pm 22$ & $80 \pm 20$ & .1 \\
\hline LV ejection fraction $(\%)$ & $55 \pm 8$ & $54 \pm 7$ & .2 \\
\hline Mean aortic valve gradient $\geq 30 \mathrm{~mm} \mathrm{Hg}$ & 17 & 15 & .3 \\
\hline$\geq$ Moderate-severe aortic regurgitation & 31 & 19 & $<.001$ \\
\hline Aortic root $\geq 4 \mathrm{~cm}$ & 36 & 25 & $<.001$ \\
\hline Ascending aorta $\geq 4 \mathrm{~cm}$ & 43 & 26 & $<.001$ \\
\hline Any BAV surgery during follow-up & 51 & 27 & $<.001$ \\
\hline Concomitant ascending aortic surgery during follow-up & 26 & 11 & $<.001$ \\
\hline
\end{tabular}

